\title{
Health and sleep problems in Cornelia de Lange Syndrome: A case control study.
}

\author{
Hall, S., Arron, K., Sloneem, J. and Oliver, C. \\ Cerebra Centre for Neurodevelopmental Disorders, \\ School of Psychology, \\ University of Birmingham
}

Please use this reference when citing this work:

Hall, S., Arron, K., Sloneem, J. and Oliver, C. (2008). Health and sleep problems in Cornelia de Lange Syndrome: A case control study. Journal of Intellectual Disability Research, 52, 458-468. (DOI: 10.1111/j.1365-2788.2008.01047.x)

The Cerebra Centre for Neurodevelopmental Disorders, School of Psychology, University of Birmingham, Edgbaston, Birmingham, B15 2TT Website: www.cndd.Bham.ac.uk E-mail: cndd-enquiries@contacts.bham.ac.uk 
Health and sleep in Cornelia de Lange syndrome

Health and sleep problems in Cornelia de Lange Syndrome: A case control study

Running Head: $\quad$ Health and sleep in Cornelia de Lange Syndrome 


\begin{abstract}
Background. Self-injury, sleep problems and health problems are commonly reported in Cornelia de Lange syndrome but there are no comparisons with appropriately matched participants. The relationship between these areas and comparison to a control group is warranted.
\end{abstract}

Method. 54 individuals with CdLS were compared to 46 participants with intellectual disability of mixed aetiology who were similar in terms of degree of intellectual disability, mobility, age and gender using informant based measures of health problems, sleep and self-injury.

Results. Participants with CdLS experienced significantly more current and lifetime health problems with eye problems and gastrointestinal disorders prominent. Although 55\% of those with CdLS experienced sleep problems this prevalence was not different from the comparison group. Sleep disorder was not associated with selfinjury in the CdLS group, skin problems were associated with severity of self-injury but not presence.

Discussion. People with CdLS experience a range of significant health problems and have more health concerns than others with the same degree of intellectual disability. Although this has been well documented in the past, the current high prevalence of health concerns indicates the need for regular health assessment and appropriate intervention. 
Health and sleep in Cornelia de Lange syndrome

\section{Introduction}

Cornelia de Lange Syndrome (CdLS) is a rare genetic syndrome characterised by facial anomalies, small stature, limb abnormalities, low birth weight and excessive hair growth (Ireland, Donnai \& Burn, 1993; Jackson, Kline, Barr \& Koch, 1993; Kline, Stanley, Belevich, Bridsky, Barr \& Jackson, 1993). Individuals with CdLS are commonly reported to have a severe to moderate degree of intellectual disability, sensory abnormalities, poor communication, autism spectrum features and compromised mobility (Berney, Ireland \& Burn, 1999; Kline et al., 1993, Oliver et $a l$. In review, Moss et al, In press). The genetic abnormality causing CdLS has been mapped for 20 to $50 \%$ of affected individuals to the NIPBL gene, located at chromosome 5p13.1 (Krantz et al., 2004; Tonkin, Wang, Lisgo, Bamshad \& Strachan, 2004) with two further gene loci on chromosome 10 and $X$ being described recently (Musio et al., 2006; Deardorff et al., 2007). Prevalence is estimated at 1 in 50,000 live births (Beck, 1976; Beck \& Fenger, 1985) although this is thought to be an underestimate with more mildly affected individuals increasingly being identified.

The NIPBL gene is expressed in the developing skeleton and soft tissue of the limbs, hands, spinal column, face and head including the ear canal, the atrial and ventricular areas of the heart, oesophagus, trachea and lungs (Tonkin et al., 2004). The compromised development in these areas may lead to the specific physical and sensory abnormalities that are often reported in CdLS involving the limbs and other bone structures, central nervous system, gastrointestinal system, peripheral senses, ears and organs such as the heart (Kline, Krantz, Goldstein, Koo \& Jackson, 2001; Luzzani, Macchini, Valade, Milani \& Selicorni, 2003). Health problems may develop from these abnormalities and are commonly described in individuals with CdLS (Jackson et al., 1993; Luzzani et al, 2003, Berg et al., 2007).

Results from published research examining health problems in CdLS are presented in table 1 and indicate that individuals with CdLS experience a number of diverse health problems with gastro-intestinal problems prominent. However, many of the studies are based on clinical examination or a review of case notes of referred samples and have not always employed reliable and valid measures and comparison groups. Communication difficulties often experienced by individuals with severe intellectual disability, mean that reporting the presence and nature of health difficulties is 
Health and sleep in Cornelia de Lange syndrome

problematic (Beange, McElduff \& Baker, 1995; Lennox \& Kerr, 1997). Studies utilising carer reports to measure health problems, such as Berney et al. (1999), Gualtieri, (1990) and Hawley et al. (1985), may facilitate identification of problems and provide insight into health issues that are of immediate concern and likely to be having impact on the individual's quality of life.

\section{+++++ Insert Table 1 here ++++++}

Previous research has indicated that individuals with intellectual disabilities are more likely to experience health problems than the general adult population (Jansen et al., 2004; Sutherland, Couch, Iacono, 2002) and the prevalence of specific health problems in people with CdLS appears to be further elevated. However, the prevalence of problems in CdLS may be comparable to those in intellectual disabilities populations e.g. the prevalence of skin conditions is 6 to $17 \%$ and epilepsy is 5 to $24 \%$ in people with intellectual disabilities (Jansen et al., 2004). As studies of the health status in CdLS have not included comparison groups, further investigation is needed in order to identify the specific health concerns associated with CdLS.

In addition to the effects of health problems on quality of life, illness may influence sleep which in turn may impact on well-being (Brylewski \& Wiggs, 1998). Empirical and anecdotal evidence suggests that sleep problems are more common in people with intellectual disabilities with 32 to $39 \%$ of people experience sleeping problems, 27 to $29 \%$ reporting settling problems and 44 to $56 \%$ waking at night (Brylewski \& Wiggs, 1998, 1999; Stores, Stores \& Buckley, 1996). Studies of sleep in CdLS have indicated that 55 to $72 \%$ of individuals experience problems, with settling difficulties described in 26\% and waking problems in 31\% (Berney et al, 1999; Gualtieri, 1990; Sarimski, 1997). However, as studies have not incorporated comparison groups it is unclear whether the prevalence of sleep problems in CdLS is higher than would be expected when compared to people with a similar degree of intellectual disability.

Individuals with CdLS are also thought to be at risk for the development of selfinjurious behaviour, with prevalence rates for self-injury being approximately 55 to $64 \%$ in people with CdLS compared to 3 to $17 \%$ in community intellectual disability populations (Berney et al., 1999; Collacott, Cooper, Branford \& McGrother, 1998; 
Hyman, Oliver \& Hall, 2002; Oliver, Murphy \& Corbett, 1987; Sloneem et al., In review). When shown, self-injury is often reported to be severe in CdLS, causing significant damage and harm (Bryson, Sakati, Nyhan \& Fish, 1971; Dossetor, Couryer \& Nicol, 1991). Environmental factors can be related to self-injury in CdLS as is the case for others with an intellectual disability (Moss, et al., 2005; Arron et al., 2006). Recent research has shown that clinically significant self-injury is not more prevalent in CdLS than a matched comparison group. However, the high prevalence is cause for concern (Sloneem et al., In review).

It has been hypothesised that self-injury may develop as a response to pain from illness or trauma as a way of blocking pain sensation (Oliver, 1993) and that experiencing health problems and sleep deprivation may influence operant processes and increase self-injury (Carr et al., 1995). A number of studies have indicated that children and adults showing self-injury are significantly more likely to have difficulties with sleeping than individuals without self-injury (Brylewski \& Wiggs, 1999; Piazza, Fisher, \& Shorer, 1997; Symons, Davis, \& Thompson, 2000). Given the reported association of CdLS with health problems, sleep difficulties and selfinjurious behaviour, the relationship between these factors in people with CdLS warrants further investigation.

To identify the health needs and sleep problems of people with CdLS, we conducted a survey to examine the presence and severity of health and sleep problems. A group of individuals with intellectual disability of mixed aetiology matched for age, gender, ability and mobility was recruited for comparison. A measure of the presence and severity of self-injurious behaviour was incorporated to examine the relationship between self-injury, health and sleep problems in both groups.

\section{Method}

\section{Participants}

75 families, who had been recruited via the CdLS Foundation parent group were contacted directly. Another 112 families were contacted via the CdLS Foundation parent group. From the 144 families who consented to the study, 54 participants with CdLS were selected based on diagnostic information, age (over two years) and distance to the research base (for full details of inclusion criteria, see Oliver et al., In 
review a). These 54 participants were visited in their usual day care setting as part of the larger study and parents and carers were sent a questionnaire pack.

Two methods of recruitment were adopted to identify a matched comparison group. Teachers and key workers of participants with CdLS identified up to two individuals who were similar to the index participant in terms of age, gender, mobility and ability. Secondly, schools and day centres that had already been visited were approached. Information packs were sent to parents and carers of the 876 individuals attending these establishments. $153(17.5 \%)$ consent forms and questionnaires were returned. Participants were included in the current study by matching to the CdLS participants. Matching criteria were age (+/- 2 years), gender, wheelchair use ('never', 'sometimes' or 'often') and self-help skills as determined by the Wessex scores (transformed into 'able', partially able' and 'not able'; Kuschlick, Blunden \& Cox, 1973). 46 participants were identified for the comparison group.

Table 2 shows participant characteristics in terms of the Wessex self help scale, mobility score, age and gender for the groups. 21 individuals in the comparison group had syndrome diagnoses including: Down Syndrome $(n=8)$, Autism $(n=3)$, Cerebral Palsy ( $\mathrm{n}=2)$, Congenital Rubella $(\mathrm{n}=1)$, Fragile X Syndrome $(\mathrm{n}=1)$, Ito Syndrome $(\mathrm{n}=1)$, Landau Kleffner Syndrome ( $\mathrm{n}=1)$, Miller Dieker Syndrome $(\mathrm{n}=1)$, Prader-Willi Syndrome $(n=1)$, Soto Syndrome $(n=1)$ and intellectual disability resultant from Reye Syndrome $(\mathrm{n}=1)$

+++++++++++ Insert Table 2 here +++++++++++

$10.9 \%$ of the comparison group participants were on anti-psychotic medication at the time of the study, $23.9 \%$ were taking anti-epileptic medication and $31.3 \%$ other forms of medication. $3.7 \%$ of the CdLS group were taking anti-psychotic medication at the time of testing, $11.1 \%$ were taking anti-epileptic medication and $42.6 \%$ other types of non-psychoactive medication.

\section{Measures}

A measure of background information regarding age, gender and diagnosis was included. 


\section{Self-injurious Behaviour}

The Challenging behaviour Interview (CBI) (Oliver et al., 2003) is a two-part interview used to assess the prevalence and severity of challenging behaviors displayed by people with intellectual disabilities. In part one, five forms of challenging behaviours (including self-injurious behaviour) are presented. Self-injury is defined as 'Non-accidental behaviors which produce temporary marks or reddening of the skin or cause bruising, bleeding or other temporary or permanent tissue damage [Examples - Self-biting, head banging, head punching or slapping, removing hair, self scratching, body hitting, eye poking or pressing]'. Informants state whether each of the behaviours have been displayed in the past month. In part two, for each behaviour identified, fourteen questions are asked to determine the severity of the behaviour. Each question has a four or five-point Likert scale, lower scores reflecting less severe behaviour. The scores for each of these questions are summed to provide an overall severity score for each behavior. Psychometric properties of the interview have been calculated, i.e. test-retest reliability, inter-rater agreement, concurrent validity and content validity were generally reported to be good. (Oliver et al. 2003).

\section{Health Questionnaire}

A health questionnaire, measuring the presence and severity of 15 health problems, was developed for use in the current study. The Tenth Revision of the International Statistical Classification of Diseases and Related Health Problems or ICD-10 (World Health Organization, 1992) was used to classify health problems. Informants are asked to rate the presence and severity $(0=$ never occurred to $3=$ severe problem $)$ of problems occurring ever in the person's life and over the last month. Scores were summed to produce an Overall Health Score indicating severity of health problems for the previous month and during the person's life. The total numbers of health problems during the person's life and the previous month were also calculated

Inter-rater reliability was collected on a sample of 24 individuals by asking two parents or carers to complete the measure independently. Mean item level reliability Kappa co-efficient for health problems ever occurring was .72 (range .32 to 1.00). Item level reliability Kappa co-efficients for the occurrence of health problems over the last month ranged from .32 to 1.00 (mean .76). Intra-class correlation co-efficient scores for the overall health problem score and total number of health problems 
Health and sleep in Cornelia de Lange syndrome

occurring over the last month were .65 and .73 respectively. Intra-class correlation co-efficient scores for the overall health problem score and total number of health problems occurring ever during the person's life were .71 and .68 respectively.

The Infant Sleep Questionnaire (ISQ; Morrell, 1999)

The Infant Sleep Questionnaire is a ten item, informant based measure of sleep in infants. The original version was adapted by substituting the phrase 'your baby' to 'the person you care for'. Informants respond to questions relating to the person's sleeping habits over the previous month. Items are collated to give an overall sleep score and the subscales of 'waking at night' and 'going to sleep', with higher scores indicating more difficulties. Comparisons of the ISQ to Richman's sleep diaries have demonstrated good concurrent validity and the test retest reliability correlation coefficient of the ISQ score is reported to be .92 (Morrell, 1999).

\section{Data Analysis}

Due to the high number of statistical tests being conducted an alpha value of less than .01 was used to indicate significance except for those tests used to evaluate comparability of the groups.

\section{Results}

Statistical analyses of the matching criteria showed no significant difference between the groups for age $(\mathrm{t}(97)=-.08, p=.94)$, gender $(\chi(1)=.14, p=.71)$, ability $(\chi(1)=$ $.67, p=.72)$ and mobility $(\chi(1)=.33, p=.85)$.

\section{Health and sleep problems between the CdLS and comparison groups}

Comparisons of the type of health difficulties shown by the two groups indicated that significantly more individuals in the CdLS group had experienced eye problems, gastrointestinal problems, problems with genitalia and a hernia during their lives, see table 3. Significantly more individuals with CdLS had also experienced gastrointestinal problems and were affected by their limb abnormalities during the previous month. 
T-test comparisons of the number of health difficulties and the Overall Health score indicated that individuals with CdLS had experienced significantly more health problems and more severe problems during their lives and the previous month than the comparison group (see table 4). No significant differences in participant's sleep scores were found between individuals in the CdLS and comparison groups.

+++++++++ Insert table 4 here +++++++++

Health problems and self-injurious behaviour

Examination of the presence of self-injurious behaviour in individuals with and without specific health problems in the CdLS group revealed that participants who had not experienced eye problems in the previous month were more likely to show self-injury, see table 5 . In the comparison group, participants with skin problems were more likely to show self-injury than those without skin problems.

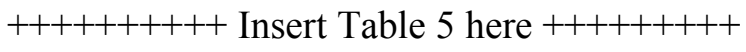

The results of comparisons of the severity of self-injury between participants who had experienced specific health problems and those who had not experienced health problems are displayed in table 6. The results for the CdLS group indicate that participants with skin problems displayed significantly more severe self-injury than those without skin problems. No significant differences were observed in the comparison group for severity of self-injury between participants with and without health problems.

\section{++++++++++++ Insert Table 6 here ++++++++++}

Sleep and self-injurious behaviour

Table 7 displays the mean sleep scores and T-test comparisons for participants showing and not showing self-injury in the CdLS and comparison group. Results reveal no significant differences in sleep scores in either group. Correlation analysis also indicated that severity of self-injury was not associated with severity of sleep 
problems in the CdLS and comparison groups (CdLS group: $r=-.03 ; p=.87$;

Comparison group: $\mathrm{r}=.20 ; \mathrm{p}=.44)$.

++++++++++ Insert table 7 here ++++++++++++

\section{Discussion}

The results of this study indicate that individuals with CdLS are likely to experience more frequent and severe health difficulties than matched individuals. Specific health problems found to be associated with CdLS include gastro-intestinal problems, eye problems and genitalia and limb abnormalities. In line with previous research, the results of the current study indicate that $71 \%$ of individuals with CdLS experience gastro-intestinal problems during their lives, with $44 \%$ of participants having been affected by gastro-intestinal problems during the previous month. The proportion of participants with CdLS displaying eye problems (67\% during their lives and 31\% during the previous month) was also similar to previous findings. The percentages of individuals with abnormalities of the limbs and genitalia in the present study were lower than results found in previous research. This may be due to the definitions employed. However, the results indicate that the prevalence of limb and genital problems is significantly higher in people with CdLS than individuals with mixed aetiology intellectual disabilities and results for the prevalence of genital abnormalities for males only in the current study (58\%) is similar to the results of previous research. Overall, the similarity of the data on health conditions in CdLS in this study to previous studies and similarity of distribution of degree intellectual disability in this sample (see Oliver at al., In review) to previously described samples suggest that this sample is representative of the population of those who have CdLS

In accordance with previous findings the current study suggests that around $75 \%$ of people with CdLS experience dental problems and $73 \%$ have problems with their ears. The prevalence rates in the CdLS group were not significantly higher than those found for individuals with mixed aetiology intellectual disabilities although it is notable that differences approached significance. Previous studies have also suggested that heart defects and epilepsy are associated with CdLS. The prevalence of these difficulties in 
Health and sleep in Cornelia de Lange syndrome

CdLS in the current study appears to be high (39\% heart defects and 33\% epilepsy). However, these figures were not significantly different to prevalence rates found for people with mixed aetiology intellectual disabilities.

Studies examining sleeping difficulties in people with CdLS have found higher rates for sleeping problems than those described in studies of people with mixed aetiology intellectual disabilities. However, this study demonstrates that when compared to matched participants with intellectual disabilities, people with CdLS are not significantly more likely to experience difficulties with sleep. $52 \%$ of carers of people with CdLS reported that the person they care for experiences mild to severe problems compared to $44 \%$ of carers of individuals in the comparison group. These findings are comparable to previous findings indicating that 55 to $72 \%$ of people with CdLS and 32 to $39 \%$ of people with intellectual disabilities have sleep problems (Berney et al., 1999; Brylewski \& Wiggs, 1998, 1999; Gualtieri, 1990; Sarimski, 1997; Stores et al., 1996).

Examinations of the relationship between the presence of self-injurious behaviour and health problems in the participants with CdLS revealed an unexpected finding.

Participants who had not experienced eye problems in the previous month were more likely to show self-injury than those who had experienced eye problems. This is in contrast to predictions that the presence not the absence of health problems might be associated with self-injurious behaviour and is difficult to interpret. The presence of sight impairment might be expected to be associated with the presence of both eye problems and self-injury. Although some research has indicated that visual impairments may be associated with self-injurious behaviour (Collacott et al., 1998; Nøttestad \& Linekar, 2001), more rigorous studies have found no association between self-injury and visual problems (Chadwick, Piroth, Walker, Bernard \& Taylor, 2000; Murphy, Hall, Oliver \& Kissi-Debra, 1999).

In CdLS Health problems appear to be associated with the severity of self-injurious behaviour rather than simply its presence. Individuals with CdLS experiencing skin problems displayed more severe self-injury than those without skin problems and a similar relationship between self-injury and dental problems approached significance. However, in both instances causal direction was not investigated. This is a novel 
finding that has not previously been reported and indicates that the presence of health problems might be associated with the severe self-injurious behaviour often reported in CdLS. Previous research indicating an association between ear infections and gastroesophagal -reflux and self-injury, and the findings reported by Luzzani et al. (2003) suggesting that gastro-intestinal difficulties might be associated with selfinjurious behaviour in CdLS, were not replicated in this study. Luzzani et al. utilised ph and endoscopy examinations to measure gastro-intestinal problems and due to the difficulties communicating the symptoms of health problems for people with severe intellectual disabilities the current study may not have identified all individuals experiencing gastro-intestinal problems. The observation that Luzzani et al. identified $65 \%$ of individuals to be currently experiencing gastro-reflux compared to $44 \%$ in this study supports this possibility. In summary, it appears that the presence of health problems in CdLS may be associated with the severity of self-injurious behaviour but not the presence.

The findings of the study indicate that individuals with CdLS do not show a different pattern of sleep problems when compared to matched individuals with mixed aetiology intellectual disabilities and sleep problems are not related to self-injury. Difficulties with sleep were not associated with presence or severity of self-injury in the CdLS or the comparison group. This is in contrast to previous research on sleep and self-injury in people with intellectual disabilities showing that children and adults showing self-injury are significantly more likely to have difficulties with sleeping than individuals without self-injury (Brylewski \& Wiggs, 1999; Piazza, Fisher, \& Shorer, 1997; Symons, Davis, \& Thompson, 2000). Differences in these findings may be explained by the use of questionnaire measurement. Informant based questionnaires rely on an awareness of the participant's sleep and carers may not always be aware of the participant's sleep disturbances. More detailed observational examinations of sleep are warranted.

Due to the limited instruments available for the measurement of the health status and sleeping behaviour of people with intellectual disabilities, in this study we employed new and adapted measures in order to examine these domains. An adapted version of Infant Sleep Questionnaire was incorporated, with demonstrated reliability and validity. However, the psychometric properties of this measure have not been 
examined for use with adults with intellectual disabilities. Although utilising carer reports of health issues provides information regarding immediate and relevant health difficulties, and can help to limit the potential threat of biased samples associated with methodologies such as clinical examination and reviews of case notes, the construct validity of carer reports remains problematic. Efforts were made to ensure the face validity and reliability of the health measure included in this study. However, further examination of the construct validity of the health questionnaire is warranted. A related methodological issue for this study was the use of a sample that is in contact with the syndrome support group and thus exposed to information about health conditions and this might not have been the case for the comparison group.

The examination of health and sleep in this study revealed that individuals with CdLS are likely to experience frequent and severe health problems. In particular, problems with the gastro-intestinal system, eyes, limbs and genitalia appear to be associated with CdLS. This high level of health problems might account for the higher ration of facial expression of negative to positive affect observed in the syndrome (Collis et al., In press). Individuals with skin problems and possibly dental problems are likely to show more severe self-injurious behaviour although causal direction needs to be extablished. Given the limited communication skills of some people with CdLS, and therefore the difficulty indicating the symptoms and existence of health problems, these findings highlight the importance of an awareness of the potential health problems for professionals working with people with CdLS. Furthermore, as nearly three quarters of individuals with CdLS are likely to experience gastro-intestinal problems, it is reasonable to suggest that robust screening processes are recommended for all people diagnosed with CdLS. 
Health and sleep in Cornelia de Lange syndrome

\section{References}

Arron, K., Oliver, C., Hall, S., Sloneem, J., Forman, D. and McClintock, K. (2006). Effects of Social Interaction on Pragmatic Communication and Self-Injurious Behavior in Cornelia de Lange syndrome. American Journal on Mental Retardation, 111, 184-192.

Bay, C., Mauk, J., Radcliffe, J., \& Kaplan, P. (1993). Mild Brachmann-Delange Syndrome - Delineation of the Clinical Phenotype, and Characteristic Behaviors in a 6-Year-Old Boy. American Journal of Medical Genetics, 47(7), 965-968.

Beange, H. P., McElduff, A., \& Baker, W. (1995). Medical disorders of adults with mental retardation: a population study. American Journal on Mental Retardation, 99, 595-604.

Beck, B. (1976). Epidemiology of Cornelia de Lange's Syndrome. Acta Paediatrica Scandinavia, 65, 631-638.

Beck, B., \& Fenger, K. (1985). Mortality, pathological findings and causes of death in the de Lange Syndrome. Acta Paediatrica Scandinavia, 74, 765-769.

Berg, K., Arron, K., Burbidge, C., Moss, J. \& Oliver, C. (2007). Carer reported contemporary health problems in people with severe learning disability and genetic syndromes. Journal of Policy and Practice in Intellectual Disabilities, 4, 120-128.

Berney, T. P., Ireland, M., \& Burn, J. (1999). Behavioural phenotype of Cornelia de Lange syndrome. Archives of Disease in Childhood, 81(4), 333-336.

Brylewski, J., \& Wiggs, L. (1998). A questionnaire survey of sleep and night-time behaviour in a community-based sample of adults with intellectual disability. Journal of Intellectual Disability Research, 42(2), 154-162.

Brylewski, J., \& Wiggs, L. (1999). Sleep problems and daytime challenging behaviour in a community-based sample of adults with intellectual disability. Journal of Intellectual Disability Research, 43, 504-512.

Bryson, Y., Sakati, N., Nyhan, W., \& Fish, C. (1971). Self-mutilative behavior in the Cornelia de Lange Syndrome. American Journal of Mental Deficiency, 76, 319-324.

Chadwick, O., Piroth, N., Walker, J., Bernard, S., \& Taylor, E. (2000). Factors affecting the risk of behaviour problems in children with severe intellectual disability. Journal of Intellectual Disability Research, 44, 108-123.

Collacott, R. A., Cooper, S. A., Branford, D., \& McGrother, C. (1998). Epidemiology of self-injurious behaviour in adults with learning disabilities. British Journal of Psychiatry, 428-432.

Collis, L., Moss, J., Jutley, J., Cornish, K. \& Oliver, C. (In press). Facial expression in Cornelia de Lange and Cri du Chat syndromes. Journal of Intellectual Disability Research. 
Deardorff, M.A., Kaur, M., Yaeger, D., Rampuria, A., Korolev, S., Pie, J., GilRodríguez, C., Arnedo, M., Loeys, B., Kline, A.D., Wilson, M., Lillquist, K., Siu, V., Ramos, F.J., Musio A, Jackson, L.S., Dorsett, D., Krantz, I.D (2007). Mutations in cohesin complex members SMC3 and SMC1A cause a mild variant of Cornelia de Lange syndrome with predominant mental retardation. American Journal of Human Genetics, 80, 485-494.

Dossetor, D. R., Couryer, S., \& Nicol, A. R. (1991). Massage for very severe selfinjurious-behavior in a girl with Cornelia-de-Lange-syndrome. Developmental Medicine and Child Neurology, 33, 636-640.

Gualtieri, C. T. (1990). Neuropsychiatry and Behavioral Pharmacology: Springer Verlag.

Hawley, P. P., Jackson, L. G., \& Kurnit, D. M. (1985). 64 patients with Brachmannde-Lange syndrome - a survey. American Journal of Medical Genetics, 20, 453-459.

Hyman, P., Oliver, C., \& Hall, S. (2002). Self-injurious behavior, self-restraint, and compulsive Behaviors in Cornelia de Lange syndrome. American Journal on Mental Retardation, 107 (2), 146-154.

Ireland, M., Donnai, D., \& Burn, J. (1993). Brachmann-deLange syndrome delineation of the clinical phenotype. American Journal of Medical Genetics, 47, 959964.

Jackson, L., Kline, A. D., Barr, M. A., \& Koch, S. (1993). De Lange-syndrome - a clinical review of 310 individuals. American Journal of Medical Genetics, 47, 940946.

Jansen, D. E. M. C., Krol, B., Groothoff, J. W. \& Post, D. (2004). People with intellectual disability and their health problems: a review of comparative studies. Journal of Intellectual Disability Research, 48, 93-102.

Kennedy, C. H. \& Meyer, K. A. (1996). Sleep deprivation, allergy symptoms, and negatively reinforced problem behavior. Journal of Applied Behavior Analysis, 29, 133-135.

Kline, A. D., Stanley, C., Belevich, J., Brodsky, K., Barr, M., \& Jackson, L. G. (1993). Developmental-data on individuals with the Brachmann-delange syndrome. American Journal of Medical Genetics, 47, 1053-1058.

Kline, A. D., Krantz, I., Goldstein, A., Koo, B., \& Jackson, L. G. (2001). Cornelia de Lange syndrome: evidence for a sensory neuropathy. American Journal of Human Genetics, 69, 567.

Kousseff, B. G., Newkirk, P., \& Root, A. W. (1994). Brachmann-delange-syndrome 1994 update. Archives of Pediatrics and Adolescent Medicine, 148, 749-755.

Krantz, I. D., McCallum, J., DeScipio, C., Kaur, M., Gillis, L. A., Yaeger, D., Jukofsky, L., Wasserman, N., Bottani, A., Morris, C. A., Nowaczyk, M. J. M., Toriello, H., Bamshad, M. J., Carey, J. C., Rappaport, E., Kawauchi, S., Lander, A. 
D., Calof, A. L., Li, H., Devoto, M. \& Jackson, L. G. (2004). Cornelia de Lange syndrome is caused by mutations in NIPBL, the human homolog of Drosophila melanogaster Nipped-B. Nature Genetics, 36, 631-635.

Kuschlick, A., Blunden R., \& Cox, G. (1973). A method of rating behaviour characteristics for use in large scale surveys of mental handicap. Psychological Medicine, 3, 466-478.

Lennox, N. G. \& Kerr, M. P. (1997). Primary health care and people with an intellectual disability: the evidence base. Journal of Intellectual Disability Research, $41,365-372$.

Luzzani, S., Macchini, F., Valade, A., Milani, D., \& Selicorni, A. (2003). Gastroesophageal reflux and Cornelia de Lange syndrome: Typical and atypical symptoms. American Journal of Medical Genetics Part A, 119A(3), 283-287.

Morrell, J. M. B. (1999). The Infant Sleep Questionnaire: A new tool to assess infant sleep problems for clinical and research purposes. Child Psychology and Psychiatry Review, 4, 20-26.

Moss, J., Oliver, C., Hall, S., Arron, K., Sloneem, J. and Petty, J. (2005). The association between environmental events and self-injurious behaviour in Cornelia de Lange syndrome. Journal of Intellectual Disability Research, 49, 269-277.

Moss, J., Kaur, G., Jephcott, L., Berg, K., Cornish, K. \& Oliver, C. (In press). The prevalence and phenomenology of autistic spectrum disorder in Cornelia de Lange and Cri du Chat syndromes. American Journal on Mental Retardation.

Murphy, G., \& Wilson, B. (1995). Self-Injurious Behaviour: A Collection of Published Papers on Prevalence, Causes and Treatment in People who are Mentally handicapped or Autistic. London: BIMH Publications.

Murphy, G., Hall, S., Oliver, C., \& Kissi-Debra, R. (1999). Identification of early selfinjurious behaviour in young children with intellectual disability. Journal of Intellectual Disability Research, 43(3), 149-163.

Musio, A., Selicorni, A., Focarelli, M.L., Gervasini, C., Milani, D., Russo, S., Vezzoni, P., Larizza, L. (2006). X-linked Cornelia de Lange syndrome owing to SMC1L1 mutations. Nature Genetics, 38, 528-530

Nøttestad, J. A., \& Linaker, O. M. (2001). Self-injurious behaviour before and after deinstitutionalisation. Journal of Intellectual Disability Research, 45, 121 - 129.

Oliver, C., McClintock, K., Hall, S, Smith, M., Dagnan, D., \& Stenfert-Kroese, B. (2003). Assessing the severity of challenging behaviour: Psychometric properties of the Challenging Behaviour Interview (CBI). Journal of Applied Research into Intellectual Disabilities, 16, 53-61.

Oliver, C., Murphy, G., \& Corbett, J. A. (1987). Self-injurious behaviour in people with mental handicap: a total population study. Journal of Mental Deficiency

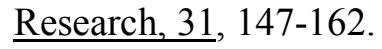


Oliver, C., Arron, K., Hall, S. and Sloneem, J. (In review) The behavioral phenotype of Cornelia de Lange syndrome. British Journal of Psychiatry.

O'Reilly, M. F. (1997). Functional analysis of episodic self-injury correlated with recurrent otitis media. Journal of Applied Behavior Analysis, 30, 165-168.

Piazza, C. C., Fisher, W., \& Kahng, S. W. (1996). A descriptive study of sleep patterns in children with mental retardation and severe behavior disorders. Developmental Medicine and Child Neurology, 38, 335-344.

Ruddick, L., \& Oliver, C. (2005). The development of a health status measure for self-report by people with intellectual disabilities. Journal of Applied Research in Intellectual Disabilities, 18(2), 143-150.

Sarimski, K. (1997). Communication, social-emotional development and parenting stress in Cornelia-de-Lange syndrome. Journal of Intellectual Disability Research, 41, $70-75$.

Sataloff, R. T., Spiegal, J. R., Hawkshaw, M., Epstein, J. M. \& Jackson, L. (1990). Cornelia de Lange syndrome. Archives of Otolaryngol, 116, 1044-1046.

Shear, C., Nyhan, W., Kirman, B., \& Stern, J. (1971). Self-mutilative behavior as a feature of the de Lange Syndrome. The Journal of Pediatrics, 78, 506-508.

Sloneem, J., Hall, S., Arron, K. and Oliver, C. Self-injurious behavior in Cornelia de Lange syndrome. American Journal on Mental Retardation.

Sommer, A. (1993). Occurrence of the Sandifer Complex in the Brachmann de Lange syndrome. American Journal of Medical Genetics, 47, 1026-1028.

Stores, R., Stores, G., \& Buckley, S. (1996). The pattern of sleep problems in children with Down's syndrome and other intellectual disabilities. Journal of Applied Research in Intellectual Disabilities, 9(2), 145-158.

Sutherland, G., Couch, M. A., \& Iacono, T. (2002). Health issues for adults with developmental disability. Research in Developmental Disabilities, 23(6), 422-445.

Symons, F., Davis, M. L., \& Thompson, T. (2000). Self-injurious behaviour and sleep disturbances in adults with developmental disabilities. Research in Developmental Disabilities, 21, 115-123.

Thompson, T., \& Caruso, M. (2002). Self-injury: knowing what we're looking for. In S. Schroeder, R., M. L. Oster-Granite \& T. Thompson (Eds.), Self-injurious Behavior (pp. 3-21). Washington DC: American Psychological Association.

Tonkin, E., Wang, T. J., Lisgo, S., Bamshad, M. J., \& Strachan, T. (2004). NIPBL, encoding a homolog of fungal Scc2-type sister chromatid cohesion proteisn and fly Nipped-B, is mutated in Cornelia de Lange syndrome. Nature Genetics, 36, 636-641. 
Health and sleep in Cornelia de Lange syndrome

Tsukahara, M., Okamoto, N., Ohashi, H., Kuwajima, K., Kondo, I., Sugie, H., Nagai, T., Naritomi, K., Hasegawa, T., Fukushima, Y., Masuno, M., \& Kuroki, Y. (1998).

Brachmann-de Lange syndrome and congenital heart disease. American Journal of Medical Genetics, 75(4), 441-442.

World Health Organization. (1992). International Statistical Classification of Diseases and Related Health Problems, 1989 Revision, Geneva. 
Health and sleep in Cornelia de Lange syndrome

\begin{tabular}{|c|c|c|c|c|c|c|c|c|c|c|c|c|c|}
\hline \multirow[b]{2}{*}{ CdLS Studies } & \multirow[b]{2}{*}{$\mathrm{N}$} & \multicolumn{12}{|c|}{ Percentage of individuals experiencing health problems } \\
\hline & & $\begin{array}{c}\operatorname{limb} \\
\text { abnorm- } \\
\text { alities }\end{array}$ & $\begin{array}{c}\text { gastro- } \\
\text { intestinal }\end{array}$ & heart & dental & $\begin{array}{l}\text { genit- } \\
\text { alia }\end{array}$ & $\begin{array}{l}\text { genito- } \\
\text { urinary }\end{array}$ & eye & ear & $\begin{array}{c}\text { respira- } \\
\text { tory }\end{array}$ & $\begin{array}{l}\text { epile- } \\
\text { psy }\end{array}$ & skin & $\begin{array}{c}\text { cleft } \\
\text { palate }\end{array}$ \\
\hline $\begin{array}{l}\text { Hawley et al., } \\
1985\end{array}$ & 64 & $33 \%$ & $71 \%$ & $28 \%$ & $93 \%$ & $\begin{array}{l}94 \% \\
\text { (males) }\end{array}$ & - & - & - & - & $14 \%$ & - & - \\
\hline $\begin{array}{l}\text { Gualtieri } \\
1990\end{array}$ & 138 & - & $41 \%$ & $15 \%$ & - & - & $8 \%$ & - & - & $18 \%$ & $25 \%$ & - & - \\
\hline $\begin{array}{l}\text { Sataloff et al., } \\
1990\end{array}$ & 45 & - & - & - & - & - & - & - & - & - & - & - & $59 \%$ \\
\hline $\begin{array}{l}\text { Ireland et al., } \\
1993\end{array}$ & 20 & $80 \%$ & $10 \%$ & $15 \%$ & - & - & - & - & - & - & $5 \%$ & - & $10 \%$ \\
\hline $\begin{array}{l}\text { Jackson et al., } \\
1993\end{array}$ & 310 & - & $48 \%$ & $25 \%$ & - & $\begin{array}{l}73 \% \\
\text { (males) }\end{array}$ & $12 \%$ & $50 \%$ & $60 \%$ & $25 \%$ & $23 \%$ & $16 \%$ & - \\
\hline $\begin{array}{l}\text { Sommer } \\
1993\end{array}$ & 17 & - & $76 \%$ & - & - & - & - & - & - & - & - & - & - \\
\hline $\begin{array}{l}\text { Kousseff et al., } \\
1994\end{array}$ & 37 & $56 \%$ & $49 \%$ & $14 \%$ & - & - & $33 \%$ & $38 \%$ & - & - & $38 \%$ & - & $21 \%$ \\
\hline $\begin{array}{l}\text { Berney et al., } \\
1999\end{array}$ & 49 & - & $67 \%$ & - & - & - & - & - & - & - & $29 \%$ & - & - \\
\hline $\begin{array}{l}\text { Tsukahara et } \\
\text { al., } 1998\end{array}$ & 50 & - & - & $26 \%$ & - & - & - & - & - & - & - & - & - \\
\hline $\begin{array}{l}\text { Luzzani et al., } \\
2003\end{array}$ & 43 & - & $65 \%$ & - & - & - & - & - & - & - & - & - & - \\
\hline
\end{tabular}

Table 1: Percentage of individuals with CdLS showing specific health problems in published studies. 
Health and sleep in Cornelia de Lange syndrome

\begin{tabular}{llcc}
\hline & & CdLS Group & $\begin{array}{c}\text { Comparison } \\
\text { Group }\end{array}$ \\
\hline Age (in years) & Mean & 13.88 & 13.74 \\
& (SD) & $(8.58)$ & $7.99)$ \\
Gender & \% Male & 46 & 50 \\
Wessex self- & \% Not able & 46 & 42 \\
Help & \% Partly able & 41 & 49 \\
& \% Able & 13 & 9 \\
Wheelchair & \% Always & 11 & 11 \\
Use & \% Occasionally & 33 & 28 \\
& \% Never & 56 & 61 \\
\hline
\end{tabular}

Table 2: Mean age and standard deviation and percentage of males, levels of ability and levels of mobility for CdLS and comparison groups 
Health and sleep in Cornelia de Lange syndrome

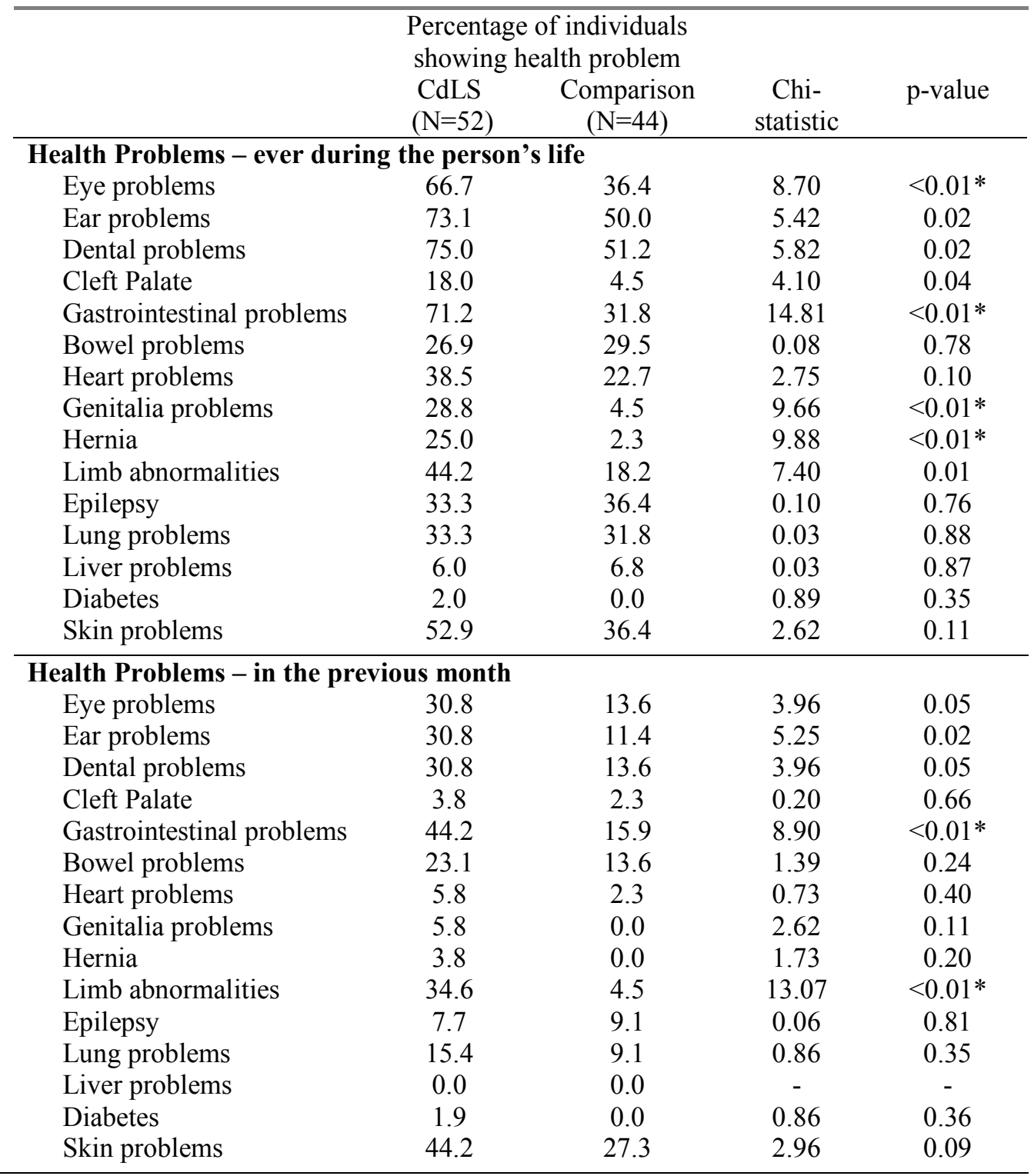

Table 3: Chi-square test results and percentage of individuals showing topographies of health problems ever and in the previous month (* indicates significant results). 
Health and sleep in Cornelia de Lange syndrome

\begin{tabular}{|c|c|c|c|c|c|}
\hline & & CdLS & Comparison & $\mathrm{T}$ & p-value \\
\hline \multicolumn{6}{|l|}{ Health Questionnaire } \\
\hline \multicolumn{6}{|c|}{ Health problems in the previous month } \\
\hline \multirow[t]{2}{*}{ Overall health score } & Mean & 4.67 & 2.00 & 4.69 & $<0.01 *$ \\
\hline & standard deviation & 3.53 & 1.93 & & \\
\hline \multirow[t]{2}{*}{ No. of health problems } & Mean & 2.82 & 1.23 & 5.13 & $<0.01 *$ \\
\hline & standard deviation & 1.91 & 1.20 & & \\
\hline \multicolumn{6}{|c|}{ Health problems during the person's life } \\
\hline \multirow[t]{2}{*}{ Overall health score } & Mean & 11.81 & 5.95 & 5.55 & $<0.01 *$ \\
\hline & standard deviation & 6.19 & 4.06 & & \\
\hline \multirow[t]{2}{*}{ No. of health problems } & Mean & 5.90 & 3.61 & 4.88 & $<0.01 *$ \\
\hline & standard deviation & 2.38 & 2.18 & & \\
\hline \multicolumn{6}{|c|}{ Infant Sleep Questionnaire } \\
\hline \multirow[t]{2}{*}{ Overall sleep score } & Mean & 12.03 & 11.67 & 0.20 & 0.85 \\
\hline & standard deviation & 9.15 & 8.54 & & \\
\hline \multirow[t]{2}{*}{ Going to bed score } & Mean & 5.58 & 5.14 & 0.45 & 0.65 \\
\hline & standard deviation & 4.73 & 4.51 & & \\
\hline \multirow[t]{2}{*}{ Waking at night score } & Mean & 6.08 & 5.95 & 0.12 & 0.90 \\
\hline & standard deviation & 5.10 & 4.82 & & \\
\hline
\end{tabular}

Table 4: T-test analyses and mean and standard deviation scores for CdLS and comparison groups for health and sleep problems. 
Health and sleep in Cornelia de Lange syndrome

\begin{tabular}{|c|c|c|c|c|c|c|c|}
\hline \multicolumn{2}{|c|}{$\begin{array}{l}\text { Health problem in } \\
\text { last month }\end{array}$} & \multirow{2}{*}{$\begin{array}{c}\begin{array}{c}\% \text { of CdLS } \\
\text { group showing } \\
\text { self-injury }\end{array} \\
25.0\end{array}$} & \multirow{2}{*}{$\begin{array}{c}\text { Chi } \\
\text { Square }\end{array}$} & \multirow{2}{*}{$\frac{P \text {-value }}{<0.01^{*}}$} & \multirow{2}{*}{$\begin{array}{c}\begin{array}{c}\% \text { of comparison } \\
\text { group showing } \\
\text { self-injury }\end{array} \\
50.0\end{array}$} & \multirow{2}{*}{$\begin{array}{c}\text { Chi } \\
\text { Square }\end{array}$} & \multirow{2}{*}{$\frac{\text { P-value }}{0.626}$} \\
\hline Eye & Present & & & & & & \\
\hline & Absent & 69.4 & & & 39.5 & & \\
\hline \multirow[t]{2}{*}{ Ear } & Present & 56.3 & 0.00 & 0.963 & 40.0 & 0.00 & 0.965 \\
\hline & Absent & 55.6 & & & 41.0 & & \\
\hline \multirow[t]{2}{*}{ Dental } & Present & 62.5 & 0.42 & 0.515 & 22.2 & 1.91 & 0.167 \\
\hline & Absent & 52.8 & & & 36.8 & & \\
\hline \multirow[t]{2}{*}{ Gastro } & Present & 60.9 & 0.44 & 0.510 & 11.1 & 0.52 & 0.469 \\
\hline & Absent & 51.7 & & & 43.2 & & \\
\hline \multirow[t]{2}{*}{ Hernia } & Present & 50.0 & 0.03 & 0.867 & - & - & - \\
\hline & Absent & 56.0 & & & 40.9 & & \\
\hline \multirow[t]{2}{*}{ Skin } & Present & 56.5 & 0.01 & 0.922 & 75.0 & 7.93 & $<0.01 *$ \\
\hline & Absent & 55.2 & & & 28.1 & & \\
\hline
\end{tabular}

Table 5: Percentage of individuals showing self-injurious behaviour with and without specific health problems in the CdLS and comparison groups. 
Health and sleep in Cornelia de Lange syndrome

\begin{tabular}{|c|c|c|c|c|c|c|c|}
\hline \multicolumn{2}{|c|}{$\begin{array}{l}\text { Health problem in } \\
\text { last month }\end{array}$} & \multirow{2}{*}{$\begin{array}{c}\text { CdLS group } \\
\text { mean self-injury } \\
\text { severity score }\end{array}$} & \multirow{3}{*}{$\begin{array}{c}\mathrm{T} \\
1.62\end{array}$} & \multirow{2}{*}{$\begin{array}{c}\text { p-value } \\
0.118\end{array}$} & \multirow{2}{*}{$\begin{array}{c}\begin{array}{c}\text { Comparison } \\
\text { group } \\
\text { mean self-injury } \\
\text { severity score }\end{array} \\
9.67\end{array}$} & \multirow{2}{*}{$\begin{array}{c}\mathrm{T} \\
1.15\end{array}$} & \multirow{2}{*}{$\begin{array}{r}\mathrm{p} \text {-value } \\
0.269\end{array}$} \\
\hline Eye & Present & & & & & & \\
\hline & Absent & 16.56 & & & 13.60 & & \\
\hline \multirow[t]{2}{*}{ Ear } & Present & 14.44 & 0.85 & 0.402 & 9.50 & 0.94 & 0.362 \\
\hline & Absent & 16.50 & & & 13.37 & & \\
\hline \multirow[t]{2}{*}{ Dental } & Present & 18.90 & -2.10 & 0.045 & 11.75 & 0.48 & 0.636 \\
\hline & Absent & 14.26 & & & 13.29 & & \\
\hline \multirow[t]{2}{*}{ Gastro } & Present & 16.21 & -0.30 & 0.765 & 11.50 & 0.39 & 0.705 \\
\hline & Absent & 15.53 & & & 13.13 & & \\
\hline \multirow[t]{2}{*}{ Hernia } & Present & 17.00 & -0.19 & 0.851 & - & - & - \\
\hline & Absent & 15.82 & & & 12.94 & & \\
\hline \multirow[t]{2}{*}{ Skin } & Present & 19.00 & -2.85 & $<0.01^{*}$ & 11.33 & 1.27 & 0.223 \\
\hline & Absent & 13.31 & & & 14.56 & & \\
\hline
\end{tabular}

Table 6: Self-injury severity scores for participants with and without health problems in the CdLS and comparison groups 
Health and sleep in Cornelia de Lange syndrome

\begin{tabular}{lcccccc}
\hline $\begin{array}{l}\text { Presence of self- } \\
\text { injury }\end{array}$ & $\begin{array}{c}\text { CdLS group } \\
\text { mean sleep score }\end{array}$ & $\mathrm{T}$ & $\mathrm{p}$-value & $\begin{array}{c}\text { Comparison group } \\
\text { mean sleep score }\end{array}$ & $\mathrm{T}$ & $\mathrm{p}$-value \\
\hline Present & 12.66 & -0.53 & 0.600 & 10.23 & 0.89 & 0.377 \\
Absent & 11.30 & & & 12.64 & &
\end{tabular}

Table 7: Mean sleep scores for participants showing and not showing self-injurious behaviour in each group. 